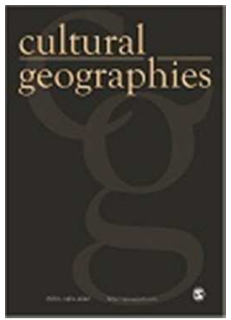

\title{
The body, the shelter, and the shebeen: An affective geography of homelessness in South Africa
}

\begin{tabular}{|r|l|}
\hline Journal: & Cultural Geographies \\
\hline Manuscript ID: & CGJ-12-0032.R2 \\
\hline Keywords: & homelessness, South Africa, affect, space, body, alcohol \\
\hline & $\begin{array}{l}\text { Geographies of homelessness mainly address issues of social exclusion, } \\
\text { especially in contexts of urban public space. Recent research focuses on } \\
\text { spatial regulation and surveillance, and strategies used by homeless people } \\
\text { to resist these forms of control and create spaces for themselves in the } \\
\text { city. Relatively little attention is paid, however, to the embodied, affective, } \\
\text { emotional and relational geographies of homelessness. We address this } \\
\text { absence through an exploration of how material spaces and practices } \\
\text { shape a sense of belonging for a group of men living in a homeless shelter } \\
\text { in Cape Town. Theorising belonging as constituted through the materialities } \\
\text { of both self-identity and social connections, we examine the three spaces } \\
\text { that are most affective in our participants' everyday lives: (i) their bodies, } \\
\text { (ii) the shelter where they live, and (iii) the shebeen (tavern) where they } \\
\text { drink. The discursive and embodied accounts of two participants in } \\
\text { particular serve as a case study that illuminates the complex ways in which } \\
\text { belonging is shaped in spaces of homeless life. These men's experiences } \\
\text { reveal some of the ambivalences and ambiguities of homelessness which } \\
\text { are only rendered visible through a theoretical lens that respects their } \\
\text { status as emotional and relational subjects, rather than as objects within } \\
\text { structures of exclusion. Drinking in particular emerges from this research } \\
\text { as an important factor in understanding the contradictory behaviours and } \\
\text { feelings in these men's daily lives. Damaging their bodies and social } \\
\text { relationships, alcohol nonetheless provides a sense of belonging by } \\
\text { facilitating both a sense of self and connections with others. }\end{array}$ \\
\hline Abstracthe
\end{tabular}

\section{SCHOLARONE"}

Manuscripts 


\title{
The body, the shelter, and the shebeen: \\ An affective geography of homelessness in South Africa \\ Shari Daya and Nicola Wilkins
}

\begin{abstract}
Introduction
Homelessness is not just about a lack of housing. It is about a lack of connectedness with friends, family and the community, and a lack of control over one's environment'. ${ }^{\prime}$
\end{abstract}

This quotation from the shelter at which our research was conducted captures something of the multi-dimensional nature of homelessness, and indeed of 'home-ness', ${ }^{2}$ in highlighting social connection, and individual autonomy and control, as central to achieving a sense of belonging. The concepts of homelessness and belonging are mutually dependent, yet are surprisingly seldom theorised as such. Existing geographies of homelessness offer much insight into the mechanisms by which homeless people are excluded from and 'transgress' into urban places, but tend to neglect the affective experiences and relationships that constitute everyday spaces of homelessness. This absence of attention to what matters to homeless people themselves dilutes their subjectivity; rather than emotional, relational beings with complex feelings, problems, ambitions and desires, they are objectified and homogenised within structures of exclusion.

To frame a more productive understanding of homelessness, we look to a wider geographical literature on place, belonging and the politics of home. One of the most useful aspects of this work is its theorisation of the roles of everyday materialities - bodies, objects, and physical practices - in creating and sustaining both the sense of self and the connections with other people that are fundamental to belonging. Informed by these insights, our analysis of the discursive and material accounts of men living in a homeless shelter in Cape Town reveals the pivotal role played by drinking, in particular, in their everyday geographies. This embodied and spatial practice illuminates some of the social and embodied ambiguities and contradictions that complicate their senses of belonging in the places that structure their daily lives.

The story we tell here is resonant with accounts of homelessness, shelter living, and homeless drinking that have been written from elsewhere - Russia, America, Britain ${ }^{3}-$ illustrating both the universality of certain experiences of homelessness and the always 
unique micro-geographies of those experiences in particular everyday spaces. We argue therefore that attempts to understand the conditions of homelessness require a sensitivity not only to the spatial strategies of homeless people excluded by the state and city-scale regulation, but also to their affective, often ambivalent engagement with spaces, things and people in their daily, mundane, intimate-scale processes of trying to make themselves feel at home.

\section{Geographies of homelessness and belonging}

Geographical literature on homelessness focuses mainly on urban settings. ${ }^{4}$ Questions of access to public space, or issues of social exclusion more broadly, form a strong thread in this literature. A major concern of this work has been to critique what is often seen as an increasingly regulated urban sphere, with homeless people subject to greater surveillance and harsher, more punitive exclusionary measures as city spaces are actively regenerated and 'improved' or as more 'organic' gentrification takes place. ${ }^{5}$

Smith's ${ }^{6}$ conceptualisation of zero-tolerance policing as 'revanchism', a policy of revenge against the poor and especially the homeless, under the pretext of reducing crime, has been particularly influential in this area of inquiry. Smith argues that homeless people in the United States and Britain have effectively been subject to practices of social cleansing, and shows how this highly authoritarian and often brutal model has been widely exported, in various guises, to countries such as South Africa, Spain, Germany, Australia, New Zealand and Argentina, among others.

Building on (and as influential as) Smith, Mitchell ${ }^{7}$ offers detailed critiques of antihomeless laws in the United States, arguing that:

by redefining what is acceptable behaviour in public space, by in effect annihilating the spaces in which the homeless must live, these laws seek simply to annihilate homeless people themselves, all in the name of recreating the city as a playground for a seemingly global capital which is ever ready to do an even better job of the annihilation of space. ${ }^{8}$

The tone of this critique against what DeVerteuil et al. ${ }^{9}$ call the 'punitive turn' in official approaches to 'street culture', ${ }^{10}$ carries through much recent research on homelessness. Often following Mitchell, ${ }^{11}$ this work frequently employs Lefebvre's notion of 'the right to the city' to denounce exclusionary policies and attempt to legitimise the presence 
and activities (sleeping, eating, cooking, and performing ablutions) of homeless people in public city spaces. $^{12}$

A parallel focus of this literature, closely linked to the discourses of claiming the right to public space, has been on the transgressive tactics employed by homeless people to create places for themselves in the city, using marginal or interstitial spaces - such as doorways, underpasses, beaches - and in the process re-drawing the boundaries of public and private, or re-mapping the lived city. Thus, Hodgetts et al. ${ }^{13}$ explore the ways in which homeless men in New Zealand use a local public library as a place of safety and social participation, and Nichols and Cázares ${ }^{14}$ consider how public transportation in the United States is similarly employed by homeless men and women as a place of shelter and safety. Others examine examines homeless people's re-shaping of public space - such as Sheehan's ${ }^{15}$ analysis of homeless people's transgressive use of an historical/tourist site as both home place and workplace - often conceptualising such accessing of public space by homeless people as 'strategies of resistance'. 16

This research is valuable in highlighting the controls to which homeless people are subject in their everyday lives, and their strategies for resisting and overcoming the regulatory and punitive structures of the state, businesses and civil society. In its focus on exclusion and transgression, however, this work sheds less light on how homeless people create spaces of inclusion. More precisely, it neglects to explore the ways in which homelessness is experienced not just as a series of obstacles to be overcome, but also in embodied and affective ways, through relationships and emotional connections.

As Cloke et al. ${ }^{17}$ point out, even work on homeless people's re-mapping of the city misses out on the aspects of their lives 'not governed by the rationalities of either regulatory strategies or the tactical rationalities of reinscription, transgression, and resistance.' These researchers 'suggest that not all of the journeys or pauses made by homeless people in the city, or the traces they leave behind, are tactical in nature'. ${ }^{18}$ A more nuanced understanding of the homeless city therefore needs readings of places of emotion and relationships as much as it needs analyses of regulation and resistance. As noted by Brickell, ${ }^{19}$ for example:

despite the fact that trauma and family conflict are acknowledged as key factors in initial exits from home, the focus of responses to homelessness remains on 'structural issues' and grief and trauma are never examined seriously as key structuring principles of homelessness. 
The omission of these fundamentally human responses to loss and social exclusion has even more profound implications; ignoring these aspects of everyday life in fact reduces the subjectivity of homeless people, or their active roles in making meaning 'through embodied and emotional interactions'. ${ }^{20}$ Imagining them only as problem-solving and transgressive entities emphasises their agency, but denies them the mundane yet vital sensory, feeling capacities that both precede and exceed such strategising and resistance.

Pain and fear, as well as reciprocity, hope, fun, and aspiration, are just some of the many embodied, emotional and relational ways in which space is made meaningful by homeless people. Some of these affective dimensions are recognised by $\mathrm{May}^{21}$ in his exploration of the 'search for a feeling of home as place' experienced by several of his homeless respondents. Recognising homeless people's feelings of homesickness, disorientation and isolation, as well as (their dreams of) belonging, safety and security are essential, May suggests, if we are to move beyond a construction of them simply as Other to the housed, and come instead to a point of understanding their experiences of home and mobility.

A handful of studies explores not just the emotions structuring experiences of homelessness, but also the ways in which feelings, identities and senses of being-in-the-world are embodied in particular ways for homeless people, providing a framework for a fuller, affective understanding of their experiences. Higate, ${ }^{22}$ for example, in his study of the physical experience of 'sleeping rough' among ex-servicemen, examines the body as a site of resource and resilience, as well as fragility and vulnerability. Kawash' ${ }^{23}$ exploration of 'the homeless body' takes a broader view, but like Higate, she emphasises the affective materialities of experiences of homelessness which take shape through publics, spaces, bodies and the ways in which they are constructed, regulated and contested. Dirt and dishevelment, possessions such as bags or trolleys, and activities such as begging, are just some of the corporeal factors that constitute the condition of homelessness. Both studies demonstrate how material and discursive constructions of the body shape the condition of homelessness - as perceived and as experienced - though these are seldom directly addressed in the literature on the topic.

Complementing these studies of homelessness, geographies of home and belonging help to fill some of the gaps that remain in theorising the connections between emotion, affect and place. Though tending to focus on questions of identity and difference on a larger scale (specifically relating to issues of citizenship, migration, transnationalism, race and ethnicity), this body of work as a whole has value for studies of homelessness. Specifically, its focus on 
the affective materialities of belonging offers particular purchase for an understanding of the multi-dimensional process of finding a place for oneself, and it thus helps to develop the insights, exemplified in the work by Higate and Kawash, into how notions of home and belonging are embodied.

Probyn's ${ }^{24}$ recent work on belonging is particularly useful here. She argues that the question of belonging expresses modes both of being and of longing or desire. This formulation allows entry into both the emotional geographies (longing and desire) that structure people's experiences of home, and into the nodes of embodied self (being) upon which feelings of belonging depend to a significant degree. Indeed Probyn ${ }^{25}$ emphasises the need to examine individuals and bodies in as much depth as we consider relationships with others if we are to understand

how people get along, how various forms of belonging are articulated, how individuals conjugate difference into manners of being, and how desires to become are played out in everyday circumstances.

Probyn's ${ }^{26}$ conceptualisation of belonging as 'something more than the term identity can catch' takes her to the notion of 'a sociology of the skin', an attentiveness to the material sites and surfaces through which allegiances may be constituted among elements that 'have no necessary "belongingness", ${ }^{27}$ These ideas emerge from and are resonant with a substantial feminist literature that destabilises the boundaries between public and private space, including for example Pratt and Rosner's ${ }^{28}$ recent work on the need for a re-connection of the global and the intimate, and the need to pay attention to feeling and affect as way of connecting 'the discourse of intimacy ... to that of the global' or the general. The body is central to such a project, and has long been of concern to feminist and gender theorists, but as Pratt and Rosner argue, the concept of affect provides something more, gesturing 'toward something excessive to both emotions and the body, ${ }^{29}$

The importance of the embodied self and its complex, affective modes of being and longing are demonstrated in numerous fields of research concerned with questions of cultural articulation. These include, to take a few examples, the geographies of citizenship, transnationalism, and migration mentioned earlier, ${ }^{30}$ as well as through geographies of young people, ${ }^{31}$ ageing ${ }^{32}$ and sexual orientation. ${ }^{33}$ In addition, the findings of Walsh et al. ${ }^{34}$ from one of the few studies on the perspectives of homeless people themselves on questions of belonging, foreground the significance of home as a place that allows the creation of an 
autonomous self particularly through bodily safety and physical privacy. For Walsh et al.'s participants, the last point emerges as the most important, ${ }^{35}$ highlighting again the primacy of the body in experiences of homelessness.

The body and its material environments are enmeshed in such accounts with the more abstract ideas of self and sociality that typically serve as the reference points for ideas of belonging. As Gorman-Murray ${ }^{36}$ argues, the narrative of self provided by a home in fact materialises the self, making it real through 'the accumulation and arrangement of meaningful possessions in... space.' Not just the body, then, but also material things and material practices are highlighted in this literature as affective elements through which belonging is shaped. Tolia-Kelly ${ }^{37}$ provides a rich example in her study of the connections between material cultures and memory for members of the South Asian diaspora. As she argues: 'Material cultures... are critical in the formation of new political identities, carving out new landscapes of belonging' ${ }^{38}$ Artefacts, and the sensory practices of looking, touching and worshipping that accompany their installation, are not incidental to feeling at home, but are 'the solidified tangible points of connection to... past narratives... landscapes and environments of belonging', 39

Similar arguments are put forward in the growing literature on the relationships between food and belonging, where the physical practices of consumption are seen as 'resonant sites for identity performance' where 'the fragile act of cultural positioning' is undertaken. ${ }^{40}$ This literature, too, tends to concern itself with issues of national and/or ethnic identity. A rather different literature on consumption and homelessness, specifically that which explores the consumption of alcohol and drugs among homeless people, provides another perspective. As Garapich ${ }^{41}$ argues in his work on Eastern European migrants in London, and as our study, too, indicates, the sense of dislocation among homeless men can result in an 'urge to seek companionship in drink' which helps 'to rebuild a broken sense of belonging and community'. Similarly, Bourgois and Schonberg's ${ }^{42}$ ethnography of 'a community of addicted bodies' in San Francisco, and Höjdestrand's ${ }^{43}$ research on how communal drinking creates solidarity among rough sleepers in St Petersburg, explore drinking and drug-taking as both coping mechanisms and a means of creating social connection, rather than simply as a problem to be solved.

Collectively then, this work is helpful in its theorisation of the material constitution of belonging. That is to say, it provides tools for understanding not simply the production of spaces of homelessness, nor merely its emotional aspects, but the ways in which the material 
and the affective are always already one dimension. It is with this insight that we move into a discussion of the nature of homelessness for our participants in a Cape Town shelter.

\section{Discursive and embodied methods}

South Africa is experiencing a crisis in housing that encompasses street homelessness and the sheltered homeless, as well as those living in shack housing. The causes lie partly in the failure of post-apartheid governments to deliver adequate housing and social support to the majority of the population, and partly in the wider dynamics of poverty and unemployment that continue to exclude many from formal housing markets. However, as Cross et al. ${ }^{44}$ point out, poverty and housing shortages do not on their own explain the presence of street and sheltered homeless people: 'if formal subsidy housing is not being accessed, self-build informal housing should offer a cheap and generally available alternative ... we ... need to ask why the street homeless are not living in shacks'.

The answers to this question need to consider such issues as social alienation, resistance to social norms, loss of support networks, addiction, personal misfortune, mental illness, and downward social mobility. However, little is known about the experiences of street and sheltered homeless people in South Africa, beyond that for the 'many who have descended into true homelessness', ${ }^{45}$ few options are available. 'Shelters are few and far between', ${ }^{46}$ and those that do exist are typically under-resourced, run by faith-based or nonprofit organisations with no state funding. While they offer some material and social support to residents, who usually pay a small fee for a shower, a meal and a bed, homeless shelters can provide only a very limited and partial solution to the widespread problems of homelessness in South African towns and cities.

The shelter at which our study was conducted was for a long time one of a 'chain' of shelters run as a non-profit organisation in the Western Cape, with most of its branches in Cape Town's suburbs. Now independent, the shelter accommodates 80 people, and at the time of our research around 68 men and 12 women were resident. In accordance with the aims of the broader project ${ }^{1}$ of which this study was a part, volunteers were initially requested for participation in a study on alcohol consumption; seven men consented to take part but no women were willing, typically giving the reason that they did not drink nor did they know anyone who did.

\footnotetext{
${ }^{1}$ This study was conducted as part of a larger project exploring the lived experiences of alcohol consumption in the Western Cape. As we explain towards the end of this section, the focus of this paper on a broader set of questions about homelessness reflects the shifts in our understanding of what was important in our participants' lives.
} 
The men who participated were interviewed informally, several times over the course of three months. To deal with one of the challenges of research on alcohol consumption - the fact that people are often reluctant or unable to articulate their experiences - the embodied methods of auto-photography ${ }^{47}$ and body tracing ${ }^{48}$ were also used. Participants received disposable cameras with which to take pictures of things and places that were meaningful to them. They also completed, with varying degrees of success, 'body books' in which they recorded feelings of pain, sadness, joy, and so on, over the course of the research. These were marked on photocopied images of their body that they themselves drew at the start of the research. The men also chose their own pseudonyms, which are used here.

While seven men formed the 'core sample' of this research, the participants in fact included a large number of the shelter residents, as well as the supervisors, the administrator, the social worker and the skills developer. This paper is therefore informed by numerous voices, but it focuses mainly on two men - BMW and Mot - whose accounts offered particular insight into the challenges of being homeless alcoholics living in a shelter. Defying the stereotypes that often accompany those labels, these men expressed the complex emotional challenges of everyday life in a homeless shelter.

As white men in a country where the homeless population is overwhelmingly black, BMW and Mot were somewhat unusual. Privileged under the apartheid regime for most of their lives, personal circumstances, including alcohol addiction, nonetheless resulted in both men being rendered homeless, estranged from their families and alienated from former friends and colleagues. Since they received a basic government pension, neither was destitute, but nor could they afford to live independently, given their limited income and lack of personal support networks. BMW and Mot's particular racial and class positioning in postapartheid South Africa - especially the ways in which they challenge assumptions about who 'the homeless' are - highlight the importance of moving beyond structural understandings of homelessness as a problem caused by failures in service delivery and entrenched poverty. The discursive and embodied accounts of our two 'protagonists' help to illuminate some of the diverse life trajectories, experiences and feelings of homeless people.

Thus, as BMW and Mot shared their stories with us, it became clear that the more interesting questions were not only about how and why they drank, but more broadly, how they responded to the multiple ways in which being homeless challenged the achievement of a sense of belonging. Drinking emerged as an important means of addressing those challenges, but also as a practice that needed to be contextualised within other aspects of their lives, rather than being isolated and narrowly conceptualised simply as problematic. The 
everyday geographies of BMW and Mot demonstrate how drinking and belonging can shape each other, in sometimes unexpected and often contradictory ways.

\section{The vulnerable spaces of the embodied self}

A sense of belonging is challenged by homelessness on the most intimate scale - that of the embodied self. Usually comprising both familiar surroundings and familial connections, home is for many people the most powerful site of identity formation. Feminist and other literatures have shown that home by no means carries unequivocally positive connotations for everyone. ${ }^{49}$ Miller, ${ }^{50}$ for example, argues that home is often 'a turbulent sea of constant negotiation rather than simply some haven for the self.'

These critiques notwithstanding, cultural narratives of what it means to 'be at home' are still pervasive and powerful. Even if, in practice, one's experience of home has not been of comfort and security, the idea of home remains generally idealised as a place where one can achieve a sense of control over the self and the immediate environment, feelings that are essential to creating feelings of belonging. As Scott ${ }^{51}$ argues, 'for most of us, home is a word loaded with emotional, spiritual, and heartfelt emotions, which run deep.... Home is where we can be ourselves'. Becoming homeless in a society where so much is invested in the idea (and ideal) of home, can therefore severely disrupt one's sense of self and autonomy. As Snow and Anderson $^{52}$ note, 'salvaging the self' is therefore often an important process for homeless people, who have been displaced from the surroundings and relationships through which their identities have been shaped and which they see as meaningful, even if their homes were not, as Sibley ${ }^{53}$ puts it, 'benign' environments.

One way in which the men in our study attempted to 'salvage' a sense of self was by providing physical proof of their existence, ${ }^{54}$ establishing their presence and legitimacy through identification documents. On several occasions residents produced their papers, unprompted by researchers. These included identification booklets, letters from past employers and even a birth certificate. One of the men, Pea, was particularly protective of his documents, always carrying them on his person out of fear of theft. On every research visit, he insisted on unpacking his rucksack to produce his latest letter from the bank or the shelter administrator, and to emphasise again how important the documents were to him.

Most striking, however, were the ways in which the self, and processes of 'salvaging', were not just documented but embodied, supporting Imrie's 55 argument that 'a person's feelings about, and experiences of, the home cannot be dissociated from their corporeality or the organic matter and material of the body.' Our participants' experiences illustrated how the 
body, 'the geography closest in, ${ }^{56}$ can be a challenging site in the context of homelessness, demanding daily negotiation. Being homeless means being physically vulnerable: to violence, weather, hard surfaces and, especially for the men in the shelter, to illness and pain, since they had access only to the most basic services in a healthcare landscape dominated by private insurance and medical providers.

For many of the men, their bodies thus constituted the first of many places in which issues of self and belonging were faced. Bodily pain was a common complaint among them. Pea, for example, often mentioned having pain in his shoulder, caused by constantly carrying all his belongings - even his blankets - in his rucksack. Not only his possessions, but also his body itself, were vulnerable to the petty threats that come with being homeless.

BMW and Mot, too, lived with and were constantly having to adjust to their corporeal vulnerability. Mot seemed to have several health conditions for which he would take pills '[as if they were] Smarties', according to one participant. He took pills for indigestion and blood pressure, and would take mild painkillers, over-the-counter headache powders which cost around R1 each, every day.

The effects of both chronic and more acute illnesses were exacerbated by the men's homelessness, which made it more difficult for them to access help and support. On one occasion during the research, BMW fell ill, and around the same time, injured himself while fixing a car for someone. He had no medicines to alleviate his pain or the symptoms of his illness, and indeed the shelter supervisor was unaware of his condition, even though BMW spent much of his time lying in bed during this period. Unable to sit in his usual spot outside, work in the garden or go for a drink, BMW suffered even more from the boredom and loneliness of everyday life in the shelter, which we discuss in more depth in next section.

For BMW and Mot, drinking was a major cause of their ill health, but also a means to alleviating both the effects of alcohol abuse and other feelings of pain and discomfort. BMW, for example, suffered from tremors, a common symptom of long-term alcohol abuse, and the only available 'cure' for his shaking was a drink - or several. His lack of control over his body caused him great unhappiness. On one occasion, having not had a drink for several days, he requested help to stop the tremors. His eyes filled with tears:

If the drink can make me stop shaking, surely the doctors can make a little pill which can do the same? I don't want drink in my life anymore, it's made me lose everything - my house, two wives, my car, my kids, everything! But I 
wake up in this dump and I'm shaking and only that drink, just one, will stop it. $^{57}$

The links between the corporeal, emotional and psychological effects of alcohol abuse have been explored in some depth in recent qualitative health research, particularly in the field of nursing. ${ }^{58}$ Smith $^{59}$ for example, notes that while the initial effects of drinking may be pleasurable, withdrawal symptoms for alcoholics are often unpleasant, leaving the drinker feeling out of control and 'not themselves', which encourages further drinking to 'find relief'. Yeh et al. ${ }^{60}$ term this pattern the 'Indulgence, Ambivalence and Attempt (IAA) cycle'. ${ }^{61}$ The body is trapped in a vicious circle where drinking seems both the illness and the cure, and their dependence on alcohol leaves the drinker feeling powerless and unable to control their addiction, which can in turn contribute to a diminished sense of self.

BMW himself made these connections, indicating, moreover, the ability of alcohol not just to give physical pleasure or relief but also to enhance his sense of self: 'After half a bottle of wine, my shakes stop and I feel more in control of my body'. ${ }^{62}$ He explained that he felt more confident when his tremors were under control, and found it easier to be sociable. On days when he had not drunk, the effect was clear - BMW looked old and frail. In contrast, both he and Mot became more talkative and outgoing after a few drinks, clearly more able to express themselves and engage with researchers, other residents and staff at the shelter. Mot, in fact, not only became more chatty, but also felt that his stutter, present before he drank, was eliminated by the effects of the alcohol.

In his body book, BMW depicted his bodily changes. In the morning before a drink, he felt insecure both physically and emotionally: he had 'the shakes' and sore eyes, and felt nervous. After a drink he noted that his shakes had stopped, and he felt relaxed and joyful.

[Figure 1 here]

BMW and Mot drank to alleviate the pain and discomfort of withdrawal and to function more effectively in their everyday social environments, but both were fully aware that their alcohol consumption was harmful. BMW was under no illusions about either the nature or the bodily effects of the 'wine' they bought at just R6 (about US\$0.50) per litre. As he said several times: 'But it's not wine, it's all chemicals, no wine in there, just different chemicals and it... really messes you up'. ${ }^{63}$ Mot concurred: 'It's real plonk, hey. No grapes in there, just chemicals. It comes in any bottle because they decant it from bigger bottles' ${ }^{64}$ 
BMW and Mot knew that they had damaged their bodies, their careers, and their family and social lives, and that they continued to be 'messed up' by drinking. Nonetheless, alcohol played an important role in providing bodily comfort and thus also greater emotional and social ease. Drinking 'salvaged' their embodied sense of self in a context of homelessness that allowed them little autonomy or control, as we discuss in the following section. The men's bodies were ambiguous spaces that, much of the time, compromised their sense of belonging, and it was often only, and paradoxically, through the damaging consumption of alcohol that they were able to regain some control and 'feel like themselves' again.

\section{The regulated spaces of the shelter}

Like their bodies, the shelter where the men lived was an ambiguous space, one where the awareness of their homeless condition was inescapable and a sense of belonging was difficult to achieve. The shelter appeared open and welcoming; the communal space was clean and light, with bright murals, trestle tables and chairs, and a television set. Outside was a large vegetable garden, maintained by residents and staff and surrounded on three sides by brightly painted shipping containers. These served as workshops for residents who had small businesses, or for socialising and card-playing on rainy days.

[Figures 2 and 3 here]

The shelter thus appeared to be a safe and pleasant space, but the men perceived it differently. As quoted above, BMW referred to it on one occasion as 'a dump', and others described it as 'grim' and 'rough'. This perception rested in part on the fact that the shelter was a controlled environment where residents were always observed, or felt that they were. Woken by a $5.30 \mathrm{am}$ bell, they had time to shower or wash before breakfast at $6.30 \mathrm{am}$. Those who did not go out to earn money then had duties such as cleaning bathrooms, watering plants or manning the gate. For the rest of the day they were largely free to do as they pleased, however, several residents complained that they constantly felt watched in the shelter, and consequently struggled to relax. This is not uncommon, as Desjarlais ${ }^{65}$ notes in his theorisation of the spatial arrangement of an American shelter, likening it to a Foucauldian panopticon where feelings of being watched encourage residents' selfregulation. Williams ${ }^{66}$ makes a similar observation, also drawing on Foucault to explain how 
the homeless shelter as institution relies upon constant observation and recording of resident actions, as well as their social and sexual histories, as techniques of power that allow staff to 'know'... residents and to measure and judge them against... the productive, sane, and moral norm.

Such discipline did not seem deliberately engineered at this shelter, and staff were always pleasant, supportive and helpful towards the residents. However, as DeVerteuil et al. ${ }^{67}$ note, 'the line between "care" and "control" is not always easy to determine.' (Johnsen and

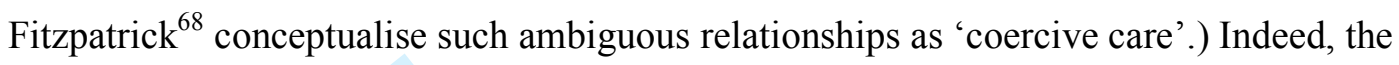
imposition of order and discipline on their living spaces, and even the constant willingness of the staff to help them, were ever-present reminders of the men's failures to be full participants in society. ${ }^{69}$

Another such reminder, and a further way in which particular behaviour was 'disciplined', took the form of a sense of shame that surrounded drinking and drunkenness at the shelter. This was illustrated by a small incident that took place one afternoon, when Mot was trying to unlock the gate to the garden. As he struggled with the padlock one of the staff joked: 'Mot normally has the magic touch but today he doesn't. Or maybe it's something else; we won't say what'. She winked at the researcher. Some of the other residents laughed and echoed the staff member: ' $J a$, let's not say what.' The implication that Mot had been drinking was clear.

Mot became irritated and defensive: 'What? What are you trying to say? Fine, you come and open it yourself then!' The lock was eventually oiled and opened, but Mot remained upset for some time - out of a sense of shame, or because he felt he had been unjustly accused, or both. Whatever the reason, it was clear from this incident that drinking was viewed negatively, even stigmatised at the shelter, and that those who drank could be excluded and reprimanded in subtle ways by both staff and fellow residents, despite drinking and drug-taking being far from exceptional among the residents.

The men's sense of not being at home in the shelter was compounded by the forms of sociality in which they were - often unwillingly - embedded, and by the lack of privacy not just from the disciplining gaze of the staff but also from close contact with other residents. The only personal spaces available to the men were their bunk-beds, closely packed in a large dormitory housing 60-odd others, and their lockers, which were often broken into. Within the sensory geography of the shelter, they were subject to seeing, hearing and even smelling others at close range, whether they wished to or not. 
[Figure 4 here]

The lack of shared identity with other residents was resolved by some of the men through an emotional distancing of themselves from these undesired, undesirable others. Among the men in our study, this took three main forms: dwelling on memories of 'normality', focusing on current family connections, and expressing hope and aspirations for a better situation in the future.

The first, reflecting and insisting on the 'normality' of their lives before entering the shelter, was often a means of establishing themselves as different, even superior to the other residents, as illustrated by several comments from BMW, including:

I'm not used to this, it's rough here. I'm struggling to adapt. ${ }^{70}$

But I'm not used to this place, hey, I wasn't bought up like this. I grew up normal, you know, we lived in a house and had a car and a dog and everything. ${ }^{71}$

BMW emphasised his separation from the other residents on several occasions, complaining about their low standards of personal hygiene, which he found disgusting: 'Some don't even wash, they don't care'. ${ }^{72}$ In another conversation he expressed amazement at residents whom he had never seen wash in the year that he had been at the shelter.

BMW hinted that his upbringing and social class made him different from the other residents, seeing his own behaviour as more mannered: 'You won't believe it, the swearing is so bad, every night there's swearing, f-this and f-that. I'm not used to this place, hey, I wasn't brought up like these people. It's really rough here'. ${ }^{73}$

Another resident, Ockie, constructed his superiority to the other residents by focusing on his previous work as a nurse. He claimed that this work had equipped him to deal with the kind of men who lived at the shelter, and seemed to see himself in the role of a staff member or carer rather than as a resident himself: 'That's why I'm ok with these guys, you know, I know how to treat them'. ${ }^{74}$ Although encouraged to elaborate, he simply repeated 'These guys here, you know', gently distancing himself from all the other residents.

Other men continued to ground their identity within the more 'normal' family and domestic spaces that BMW invoked. That they located their own identities in these spaces, 
rather than in the shelter where they spent far more time, was demonstrated by the many pictures of family gatherings in the auto-photographic part of this study. Most of these were taken at the homes of family members on days spent away from the shelter. These photographs suggested that the emotional geographies of family connections and domestic spaces were more important in shaping a sense of belonging than the constrained geographies of the shelter, where constant vigilance and protective strategies were required.

Similarly, Mot gave an account of his granddaughter that demonstrated the depth of his emotional investment in his family, even though he had little actual contact with them, and that only on their terms. He expressed vividly his delight in being with his granddaughter, and his pain at being kept at a distance from her by his daughter:

She's seven, and she's magic. $J a$, it's like magic you know, especially when I see little Kirsten and I think, jeez, you know it's unreal, I get cold shivers you know, it's just that I love her so much. And it's like I can't really spend time with her 'cause somehow I think my daughter doesn't want me to spend time with her, you know, so it's just a visit, like when she comes here and it's maybe half an hour, you know? ${ }^{75}$

BMW was even more isolated from his family members. He had a young daughter with a woman in Port Elizabeth, but said he hadn't seen them for five years. He wondered aloud whether he should go back, 'but maybe she's married now, maybe she won't want to see me ${ }^{76}$ His son, too, in his 40s and living in Johannesburg with his three children, had no interest in seeing BMW.

For BMW and Mot, alcoholism was a central cause of estrangement from their families. Having exhausted, through their drinking and drunken behaviours, 'the patience or resources otherwise available in their social network ${ }^{77}$ and having consequently become homeless, BMW and Mot had little choice but to take up accommodation in this shelter. While neither felt able to stop drinking to create a better chance of re-connection, family remained a source of both comfort and pain to the two men.

Finally, emotional distance for BMW and Mot was also created through aspiration. They talked about moving out of the shelter, where they had been living for around one and five years, respectively. Reliant on one another for company and support, they did not want to be separated, and imagined finding a place where they could live together. This 'just needs to 
be one room with some mattresses. We can buy a small hotplate and some pots and we'll be fine. Maybe somewhere near the sea but we don't care - just somewhere away from here' ${ }^{78}$

This move was not a concrete plan, but rather a dream than enabled them to deal with their circumstances at difficult times. At times when they felt more at ease in the shelter, the aspiration to move was put aside. This was made clear a few weeks later when Mot, asked how their plans to move were going, replied: ' $J a$, I guess this is my home now. I've grown attached to this place and I'd hate to leave it'. ${ }^{79}$ Although the two men would no doubt have liked to find more independent housing, they had limited financial resources. Moreover, having lived in the shelter for so long they were unsure whether they could survive on their own. Being able to hold on to the possibility, however, allowed them both a sense of hope that made their present environment tolerable.

These three strategies of emotional distancing from the controlled environment and enforced socialities of the shelter, were often encountered during the research. Our work thus supports the suggestions of others, such as Cloke et al. ${ }^{80}$ and May, ${ }^{81}$ that the rules governing life in shelters and hostels can undermine residents' senses of privacy, autonomy and control, and that in these spaces 'it is difficult to find anything equating to a sense of home'. ${ }^{82}$ A more powerful, physical form of distancing, however, was also common for our two 'protagonists', BMW and Mot. For them, the unpleasantness of the shelter was countered through frequent visits to a nearby shebeen, a space which was as ambiguous and contradictory as those of their bodies and the shelter, but which facilitated most powerfully a sense of belonging for the two men.

\section{The convivial spaces of the shebeen}

One of the most regular complaints about shelter life was that it was boring. This was mentioned in several different contexts, but particularly, for BMW and Mot, as an explanation for their drinking.

Every day is the same, we just sit here and do nothing. Like today we work and we do our duties there in the dorms and we clean the bathroom but then we're bored. So we borrow ten rand from that guy, a few bucks from that guy and we go and have a dop [drink]... It helps break up the day. In fact I could go for another now. ${ }^{83}$ 
At least we read sometimes, when we can read, that is, but otherwise it is so boring! $!^{84}$

Although they did in fact read a great deal, did crossword puzzles and worked in the vegetable garden to pass the time, their days often dragged at the shelter. The shebeen provided a space of relief from the monotony, with different forms of sociality, and the added benefit of alcohol to lift their moods. As Mot explained, 'to go sit and have a few sparks [drinks] and a chat makes the day go faster' ${ }^{85}$

The shebeen where they most often went for a 'spark' was about fifteen minutes' walk from the shelter, in a tiny, densely populated informal settlement. It was described by the men as a 'rough', 'terrible' and 'shocking' place that was also 'dirty' and 'crowded', and indeed the space was oppressive and unpleasant in many respects.

BMW and Mot led us... into the shebeen; it was just a woman's shack from which she sells alcohol. The roof is low and made from chipboard and heavyduty plastic. The door is made of thick wood and is so sunk in the mud that I can't imagine it being able to close. The first room we step into is roughly $2 \mathrm{~m}$ x $5 \mathrm{~m}$ and nine people sit on plastic chairs or a wooden bench around its edge. One woman is smoking a pipe and the others smoke communal cigarettes the smoke makes the room hazy and a thick layer is trapped by the low ceiling. ${ }^{86}$

[Figures 5, 6 and 7 here]

Despite the impoverished surroundings, the men received a cheerful welcome from those already present, and the shebeen had a certain warmth and homeliness.

As we walk in Mot is greeted with a cheerful chorus of 'Oupa! [Grandad] How are you? Come and join us.' Mot takes us through to the next room, down a step into a darker and more stuffy room although this one smells pleasantly of frying onions and garlic. There is no floor to the shack and so the rooms feel damp and unstable. The walls are made of different materials, some wood and others chipboard. There are white lace curtains on the windows, which make the inside room even darker. ${ }^{87}$ 
In seeming contradiction to their negative descriptions of the shebeen, quoted above, Mot compared it favourably to the shelter on one occasion: 'After a drink I feel lighter and less down, and then we come back [to the shelter] and I think, ugh, back to the same old grime again'. ${ }^{88}$ This seemed ironic since objectively, the shebeen was far more 'grimy' than the shelter. However, visiting the shebeen with BMW and Mot on several occasions, it became clear that for them this was a far more liberating space than the shelter. This was partly because the shebeen was simply a cheerier, more affable place, as the men pointed out:

It's nice to go have a spark. We'll often go and sit there for a few hours and relax. Everyone knows us there so we just sit and talk nonsense. ${ }^{89}$

It's nice to go and sit there. Sometimes Mot starts singing golden oldies and gets everyone to join in. ${ }^{90}$

Their sense of belonging at the shebeen was facilitated, too, by the ease with which their drinking, an important aspect of both their lives, was accepted. This was in stark contrast to the way in which drinking was viewed at the shelter, where, as suggested in the previous section, there was a general sense of shame surrounding drinking, and a reluctance to speak about it, such that gestures or allusions tended to be used instead by both staff and residents. BMW, for example, rather than being explicit, would tilt his hand towards his mouth to indicate that he had been drinking. Mot would use euphemisms, such as speaking about one weekend being 'oops', indicating that he had been drunk and was now hung over. On another occasion, Mot arrived drunk at an interview, and his shame was evident:

Mot appears - he is holding his left side and in a whisper says to me, 'I'm sorry but I'm very drunk'... and again repeats 'I'm so drunk,' while looking around to make sure no-one can hear him. 'It's ok,' I say. ' I'm coming back on Tuesday and I'd like to talk to you then.' He agrees and winks at me, again apologising for being drunk. ${ }^{91}$

At the shebeen, of course, drinking was accepted and welcomed and the men had no need to feel judged, since everyone was engaged in similar drinking behaviour. Not only did alcohol provide bodily ease and restore the men's sense of self, as discussed above, but the 
shebeen enabled a sense of social belonging through conversation and shared activity, which were not available in the same way at the shelter. As emergent geographical work has begun to show, the consumption of alcohol can play a significant role in shaping diverse forms of identity and belonging ${ }^{92}$ and drinking itself is often constitutive of a sense of community ${ }^{93}$ and of feeling at home..$^{94}$

Finally, the location of the shebeen in an impoverished informal settlement also conferred on the men a certain status. Both expressed pity for the people living in the settlement, since they had no electricity or running water, and only four toilets shared among 200 residents, according to BMW. This environment was a reminder to our participants of their own good fortune in having accommodation at the shelter, and an example of how their lives might be worse, a not uncommon response among those whose situations are uncertain. ${ }^{95}$ Although they felt a sense of belonging at the shebeen, they did not identify with the settlement dwellers. Rather, by being able to visit as and when they wished, they were able to exercise control over their environment and thus establish more firmly an identity of their own choosing.

This is perhaps the most important point - that the men entered the shebeen on their own terms. As they repeated several times during the research, they drank not with the intention of getting drunk - i.e. losing control - but rather 'to relax'. The space of the shebeen, then, was one in which they felt most in control. They entered and left freely, they enjoyed themselves while they were there, and no one was overly watchful or critical of their behaviour. Although their relationships with fellow shebeen-goers were contradictory, both creating a sense of belonging and actively working against the men's stated desires to break their dependence on alcohol, the shebeen was the most liberating space for BMW and Mot. It was a powerfully affective space where they felt at ease and accepted, stimulated and unashamed, in clear contrast to the experiences of pain, loneliness, boredom and embarrassment that characterised most other spaces of their everyday geographies.

\section{Conclusion}

BMW and Mot's stories clearly demonstrate that what matters most to them is less the rational development of strategies for accessing space, and more feelings of belonging, comfort and connection with others. While they yearned for such security, these feelings were difficult for them to achieve in a homeless shelter that offered little privacy or freedom. The everyday living spaces of the shelter and even the intimate spaces of their own bodies, instead of being comfortable, 'homely' places, had constantly to be negotiated and managed. 
Indeed, feelings of being at home were compromised or prevented in many different ways in these spaces - through pain, through noise and smells, through constant surveillance and judgemental gazes.

The shebeen, by contrast, was a space where a sense of belonging could be achieved, despite the basic, even unpleasant surroundings and the damaging effects of the alcohol that they consumed there. For BMW and Mot, a sense of feeling in control of their own bodies, feeling responsible for their own behaviour and having the freedom to choose their own environment, were crucial in creating this sense of belonging. Although the comforts they found in the shebeen were often ambiguous and even contradictory, it was the most liberating place available to the two men, and the one where they were most able to feel in control and at home.

The accounts of these two men highlight the importance of exploring the affective dimensions of homeless people's lives, connecting their embodied and material experiences with their emotions, feelings and desires, in order to try and understand them as more than simply socially and spatially excluded Others. These affective dimensions of everyday life shape the condition and experience of homelessness as much, if not more than, its structural causes and effects. While it is obviously important to consider and critique the social and political dynamics that produce and exacerbate homelessness, this must be done with the awareness that the experience of being homeless is different for different people, ${ }^{96}$ and that what is lacking for many homeless people is not simply money or shelter, but also, and more fundamentally, a sense of belonging that is to be found in both material and emotional comforts.

\section{Acknowledgements}

This project was funded by a grant from the Economic and Social Science Research Council and the Department for International Development, grant number RES-167-25-0473, through King's College London and the African Centre for Cities (ACC) at the University of Cape Town (UCT), as well as by a joint grant from the British Academy and the Association of Commonwealth Universities. Many thanks to Clare Herrick and Susan Parnell for supporting the research. The writing of the article was supported by a sabbatical grant from the Urban Studies Foundation. Thanks to the entire alcohol project team at UCT for feedback at various stages of the research, and to Ash Amin for insightful comments on an earlier draft of this paper. Thanks also to the staff and residents at the homeless shelter at which the research was done; without their willing participation the project could not have been undertaken. 


\footnotetext{
${ }^{1}$ Shelter, information pamphlet (2011).

${ }^{2}$ C. Robinson, “I think home is more than a building": young homeless people on the cusp of home, self and something else', Urban Policy and Research 20/1 (2002), pp. 27-38.

${ }^{3}$ T. Höjdestrand, Needed by Nobody: Homelessness and Humanness in Post-Socialist Russia (Ithaca and London, Cornell University Press, 2009); S. Kawash, 'The homeless body', Public Culture 10/2 (1998), pp. 319-339; P. Cloke, J. May and S. Johnsen, 'Performativity and affect in the homeless city', Environment and Planning D: Society and Space 26 (2008), pp.241-263.

${ }^{4}$ However, see P. Cloke and R.C. Widowfield, 'The hidden and emerging spaces of rural homelessness', Environment and Planning A 32 (2000), pp. 77-90; P. Cloke, P. Milbourne and R. Widowfield, Rural Homelessness: Issues, Experiences and Policy Responses (Bristol, Policy, 2002); and P. Cloke, P. Milbourne and R. Widowfield, 'The complex mobilities of homeless people in rural England', Geoforum 34/1 (2003), pp. 21-35.
}

${ }^{5}$ For a recent review, see S. Herbert, 'Contemporary geographies of exclusion III: to assist or punish?', Progress in Human Geography 35/2 (2011), pp. 256-263.

${ }^{6} \mathrm{~N}$. Smith, 'Global social cleansing: postliberal revanchism and the export of zero tolerance', Social Justice 28/3 (2001), pp. 68-74.

${ }^{7}$ D. Mitchell, 'The annihilation of space by law: the roots and implications of anti-homeless laws in the United States', Antipode 29/3 (1997), pp. 303-335; D. Mitchell and N. Heynan, 'The geography of survival and the right to the city: speculations on surveillance, legal innovation, and the criminalization of intervention', Urban Geography 30/6 (2009), pp. 611-632; and D. Mitchell, 'Homelessness, American style', Urban Geography 32/7 (2011), pp. 933-956.

${ }^{8}$ Mitchell, 'The annihilation of space', p. 305.

${ }^{9}$ G. DeVerteuil, J. May and J. von Mahs, 'Complexity not collapse: recasting the geographies of homelessness in a "punitive” age', Progress in Human Geography 33/5 (2009), pp. 646-666.

${ }^{10}$ S. Johnsen and S. Fitzpatrick, 'Revanchist sanitation or coercive care? The use of enforcement to combat begging, street drinking and rough sleeping in England', Urban Studies 47/8 (2010), pp. 17031723.

${ }^{11}$ D. Mitchell, The Right to the City: Social Justice and the Fight for Public Space (New York, Guildford, 2003). 


\begin{abstract}
${ }^{12}$ For example, see R.M. Feldman and S. Stall, The Dignity of Resistance: Women Residents' Activism in Chicago Public Housing (Cambridge, Cambridge University Press, 2004); D. Hodgetts, O. Stolte, K. Chamberlain, A. Radley, L. Nikora, E. Nabalarua and S. Groot, 'A trip to the library: homelessness and social inclusion', Social and Cultural Geography 9/8 (2008), pp. 933-953; F. Klodawsky, 'Home spaces and rights to the city: thinking social justice for chronically homeless women', Urban Geography 30/6 (2009), pp. 591-610; T. Sparks, 'Broke not broken: rights, privacy, and homelessness in Seattle', Urban Geography 31/6 (2010), pp. 842-862; A. Sugranyes and C. Mathivet, eds., Cities for All: Proposals and Experiences towards the Right to the City (Santiago, Habitat International Coalition, 2010). See also K.A. Attoh, 'What kind of right is the right to the city?', Progress in Human Geography 35/5 (2011), pp.669-685 for a recent critique of the uses and abuses of Lefebvre's concept.

${ }^{13}$ Hodgetts et al., 'A trip to the library'.

${ }^{14}$ L. Nichols and F. Cázares, 'Homelessness and the mobile shelter system: public transportation as shelter', Journal of Social Policy 40/2 (2011), pp. 333-350.

${ }^{15}$ R. Sheehan, “'I'm protective of this yard”: long-term homeless persons' construction of home place and workplace in a historical public space', Social and Cultural Geography 11/6 (2010), pp. 539-558.
\end{abstract}

${ }^{16}$ R. Casey, R. Goudie and K. Reeve, Homeless women in public spaces: strategies of resistance, Housing Studies 23/6 (2008), pp. 899-916.

${ }^{17}$ Cloke et al., 'Performativity and affect', p. 245.

${ }^{18}$ Cloke et al., 'Performativity and affect', p. 245.

${ }^{19}$ K. Brickell, “"Mapping” and "doing” critical geographies of home', Progress in Human Geography 36/2 (2011), pp. 225-244, quotation p. 231, citing Dovey (1985).

${ }^{20}$ Cloke et al., 'Performativity and affect', p. 245.

${ }^{21} \mathrm{~J}$. May, 'Of nomads and vagrants: single homelessness and narratives of home as place', Environment and Planning D: Society and Space 18 (2000), pp. 737-759, quotation p. 749.

${ }^{22}$ P. Higate, 'Ex-servicemen on the road: travel and homelessness', The Sociological Review $\mathbf{4 8 / 3}$ (2000), pp. 331-347.

${ }^{23}$ Kawash, 'The homeless body'. 
${ }^{24}$ E. Probyn, Outside Belongings (New York, Routledge, 1996).

${ }^{25}$ Probyn, Outside Belongings, p. 5.

${ }^{26}$ Probyn, Outside Belongings, p. 5, italics in original.

${ }^{27}$ Probyn, Outside Belongings, p. 5, citing Hall (1986).

${ }^{28}$ G. Pratt and V. Rosner, The Global and the Intimate: Feminism in our Time (New York and Chichester, Columbia University Press, 2012), p. 5.

${ }^{29}$ Pratt and Rosner, The Global and the Intimate, p.6.

${ }^{30}$ See M. Gilmartin, 'Migration, identity and belonging', Geography Compass 2/6 (2008), pp. 18371852 , for a review.

${ }^{31}$ Robinson, “"I think home is more than a building”".

32 J-S Marcoux, 'The 'casser maison' ritual: constructing the self by emptying the home', Journal of Material Culture 6/2 (2001), pp. 213-235; and A. Varley, 'A place like this? Stories of dementia, home, and the self', Environment and Planning D: Society and Space 26/1 (2008), pp. 47-67.

${ }^{33}$ A. Gorman-Murray, 'Contesting domestic ideals: queering the Australian home', Australian Geographer 38/2 (2007), pp. 195-213; and A. Gorman-Murray, 'Reconciling self: gay men and lesbians using domestic materiality for identity management', Social and Cultural Geography $\mathbf{9 / 3}$ (2008), pp. 283-301.

${ }^{34}$ C.A. Walsh, G.E. Rutherford and N. Kuzmak, 'Characteristics of home: perspectives of women who are homeless’, The Qualitative Report 14/2 (2009), pp. 299-317.

${ }^{35}$ See also J.C. Williams, 'Geography of the homeless shelter: staff surveillance and resident resistance', Urban Anthropology and Studies of Cultural Systems and World Economic Development 25/1 (1996), pp. 75-113; and Sparks, 'Broke not broken'.

${ }^{36}$ Gorman-Murray, 'Reconciling self’, p. 283

${ }^{37}$ D. Tolia-Kelly, 'Locating processes of identification: studying the precipitates of re-memory through artefacts in the British Asian home', Transactions of the Institute of British Geographers 29/3 (2004), pp. 314-329. 


\footnotetext{
${ }^{38}$ Tolia-Kelly, 'Locating processes of identification', p. 315.

${ }^{39}$ Tolia-Kelly, 'Locating processes of identification', p. 319.

${ }^{40} \mathrm{~J}$. Duruz, 'Home cooking, nostalgia, and the purchase of tradition', Traditional Dwellings and Settlements Review XII/11 (2001), pp. 21-32, quotation p. 22. See also M. Rabikowska and K. Burrell, 'The material worlds of recent Polish migrants: transnationalism, food, shops and home', in K. Burrell, ed., Polish Migration to the UK in the 'New' European Union: After 2004 (Farnham, Ashgate, 2009), pp. 211-239; and J. Everts, 'Consuming and living the corner shop: belonging, remembering, socialising', Social and Cultural Geography 11/8 (2010), pp. 847-863.
}

${ }^{41}$ M. P. Garapich, The Unwanted: Social and Cultural Determinants of Homelessness and Alcohol Abuse among Eastern European Migrants in London: Research Report (Roehampton University and University of Surrey, Centre for Research on Nationalism, Ethnicity and Multiculturalism (CRONEM) n.d.), p. 29.

${ }^{42}$ P. Bourgois and J. Schonberg, Righteous Dopefiend (Berkeley, University of California Press, 2009), p. 82.

${ }^{43}$ Höjdestrand, 'Needed by Nobody'.

${ }^{44}$ C. Cross, J. Seager, J. Erasmus, C. Ward, and M. Donovan, 'Skeletons at the feast: a review street homelessness in South Africa and other world regions', Development Southern Africa 27/1 (2010) pp. 5-20, quotation p. 7.

${ }^{45}$ Cross et al., Skeletons at the feast', p. 5 .

${ }^{46} \mathrm{P}$. Meth, 'The shelter dilemma for women experiencing domestic violence', Agenda 48 (2001), pp. 113-119, quotation p. 117.

${ }^{47}$ This is a method increasingly used in research on homelessness, for example by S. Johnsen, J. May and P. Cloke, 'Imag(in)ing homeless places: using auto-photography to (re)examine the geographies of homelessness', Area 40/2 (2008), pp. 194-207; A. Radley, K. Chamberlain, D. Hodgetts, O. Stolte and S. Groot, 'From means to occasion: walking in the life of homeless people', Visual Studies 25/1 (2010), pp. 36-45; K. Bukowski and S. Buetow, 'Making the invisible visible: a Photovoice exploration of women's health and lives in central Auckland', Social Science and Medicine 72/5 (2011), pp. 739-746. See also S. Pink, Doing Visual Ethnography: Images, Media and Representation in Research (London, Sage, 2007). 


\footnotetext{
${ }^{48}$ A. Crawford, 'If "the body keeps score": mapping the disassociated body in trauma narrative, intervention and theory', University of Toronto Quarterly 79/2 (2010), pp.702-719.

${ }^{49}$ See K. Brickell, “"Mapping” and “doing”, for a detailed review

${ }^{50}$ D. Miller, 'Behind closed doors', in D. Miller, ed., Home Possessions: Material Culture behind Closed Doors (Oxford and New York, Berg, 2001) p. 4.

${ }^{51}$ S. Scott, All Our Sisters: Stories of Homeless Women in Canada (Toronto, Higher Education University of Toronto Press, Toronto, 2008), p. 15.

${ }^{52}$ D. Snow and L. Anderson, Down on their Luck: A Study of Homeless Street People (Oxford, University of California Press, 1993).

${ }^{53}$ D. Sibley, Geographies of Exclusion: Society and Difference in the West (London, Routledge, 1995), p. 93.
}

${ }^{54}$ K. Boydell, P. Goering and T. Morrell-Bellai, 'Narratives of identity: re-representation of self in people who are homeless', Qualitative Health Research 10/1 (2000), pp. 26-38.

${ }^{55}$ R. Imrie, 'Disability, embodiment and the meaning of the home', Housing Studies 19/5 (2004), pp. 745-763, quotation p. 745.

${ }^{56}$ A. Rich, Blood, Bread and Poetry: Selected Prose 1979-1985 (London, Norton, 1986), p. 212.

${ }^{57}$ Interview at shelter, 8 June 2011.

${ }^{58}$ R.F. Zakrewski and M.A. Hector, 'The lived experiences of alcohol addiction: men of Alcoholics Anonymous', Issues in Mental Health Nursing 25/1 (2004), pp. 61-77.

${ }^{59}$ B. Smith, 'The problem drinker's lived experience of suffering: an exploration using hermeneutic phenomenology', Journal of Advanced Nursing 27 (1998), pp. 213-222, quotation p. 217.

${ }^{60}$ M.Y. Yeh, H.L. Che and S.M. Wu, 'An ongoing process: a qualitative study of how the alcoholdependent free themselves of addiction through progressive abstinence', BMC Psychiatry 9/76 (2009), pp. 9-76.

${ }^{61}$ See also G.V. Mohatt, S.M. Rasmus, L. Thomas, J. Allen, K. Hazel and G.A. Marlatt, 'Risk, resilience, and natural recovery: a model of recovery from Alcohol abuse for Alaska Natives', Addiction 103/2 (2008), pp. 205-215. 
${ }^{62}$ Interview walking back from shebeen, 16 August 2011.

${ }^{63}$ Interview at shelter, 18 July 2011.

${ }^{64}$ Interview at shelter, 8 August 2011.

${ }^{65}$ R. Desjarlais, Shelter Blues: Sanity and Selfhood among the Homeless (Philadelphia, University of Philadelphia Press, 1997).

${ }^{66}$ Williams, 'Geography of the homeless shelter'.

${ }^{67}$ DeVerteuil et al., 'Complexity not collapse', p. 652.

${ }^{68}$ Johnsen and Fitzpatrick, 'Revanchist sanitation'.

${ }^{69}$ A. Watson, Street Addicts in the Political Economy (Philadelphia: Temple University Press, 1993).

${ }^{70}$ Interview at shelter, 14 July 2011.

${ }^{71}$ Interview at shelter, 19 July 2011.

${ }^{72}$ Interview at shelter, 14 July 2011.

${ }^{73}$ BMW, interview at shelter, 19 July 2011.

${ }^{74}$ Ockie, interview at shelter, 14 July 2011.

${ }^{75}$ Interview at shelter, 12 July 2011.

${ }^{76}$ Interview at shelter, 14 July 2011.

${ }^{77}$ Snow and Anderson Down on their Luck, p. 356.

${ }^{78}$ Mot, interview at shelter, 8 August 2011.

${ }^{79}$ Interview at shelter, 22 August 2011.

${ }^{80}$ Cloke et al., 'Performativity and affect'. 


\footnotetext{
${ }^{81}$ May, 'Of nomads and vagrants'.

${ }^{82}$ May, 'Of nomads and vagrants', p. 755.

${ }^{83}$ Mot, interview at shelter, 26 July 2011.

${ }^{84}$ BMW, interview at shelter, 26 July 2011.

${ }^{85}$ Interview at shelter, 8 August 2011.

${ }^{86}$ Field notes, 23 August 2011.

${ }^{87}$ Field notes, 23 August 2011.

${ }^{88}$ Interview at shelter, 8 August 2011.

${ }^{89}$ Mot, interview at shelter, 5 August 2011.

${ }^{90} \mathrm{BMW}$, interview at shelter, 8 August 2011.

${ }^{91}$ Field notes, 8 July 2011.

92 J. Dyson, 'Experiences of alcohol dependence: a qualitative study', Journal of Family Health Care 17/6 (2007), pp. 211-214.
}

${ }^{93}$ A. Latham, 'Urbanity, lifestyle and making sense of the new urban cultural economy: notes from Auckland, New Zealand', Urban Studies 40/9 (2003), pp. 1699-1724; A. Latham and D. McCormack, 'Moving cities: rethinking the materialities of urban geographies', Progress in Human Geography 28/6 (2004), pp. 701-724; T. Edensor, 'Reconsidering national temporalities: institutional times, everyday routines, serial spaces and synchronicities', European Journal of Social Theory $9 / 4$ (2006), pp. 525545; S.L. Holloway, G. Valentine and M. Jayne, 'Masculinities, femininities and the geographies of public and private drinking landscapes', Geoforum 40/5 (2009), pp. 821-831.

${ }^{94}$ G. Valentine, S. Holloway and M. Jayne, 'Drinking places: young people and cultures of alcohol consumption in rural environments', Journal of Rural Studies 24/1 (2009), pp. 28-40; S. Holloway, M. Jayne and G. Valentine, “'Sainsbury's is my local”: English alcohol policy, domestic drinking practices and the meaning of home', Transactions of the Institute of British Geographers 33/4 (2008), pp. 532547. 


\footnotetext{
${ }^{95}$ R. Jahiel, 'The situation of homelessness', in R. Bingham, R. Green and S. White, eds., The Homeless in Contemporary Society (London, Sage, 1987); J. Wardhaugh, 'The unaccomodated woman: home, homelessness and identity', The Sociological Review 47/1 (1999), pp. 91-109; and K. Boydell et al. 'Narratives of identity'.

${ }^{96}$ J. May, P. Cloke and S. Johnsen, 'Alternative cartographies of homelessness: rendering visible British women's experiences of “visible” homelessness', Gender, Place and Culture 14/2 (2007), pp. 121-140, quotation p. 136.
}

\begin{abstract}
Biographical note
Shari Daya is a lecturer in Human Geography in the Environmental and Geographical Science Department at the University of Cape Town. She explores the embodied and emotional geographies of everyday life in the global South, particularly India and South Africa.
\end{abstract}

Nicola Wilkins has recently completed her Honours degree in the Environmental and Geographical Science Department at the University of Cape Town. Her research explored geographies of drinking and homelessness in Cape Town. 
Page 29 of 36

cultural geographies
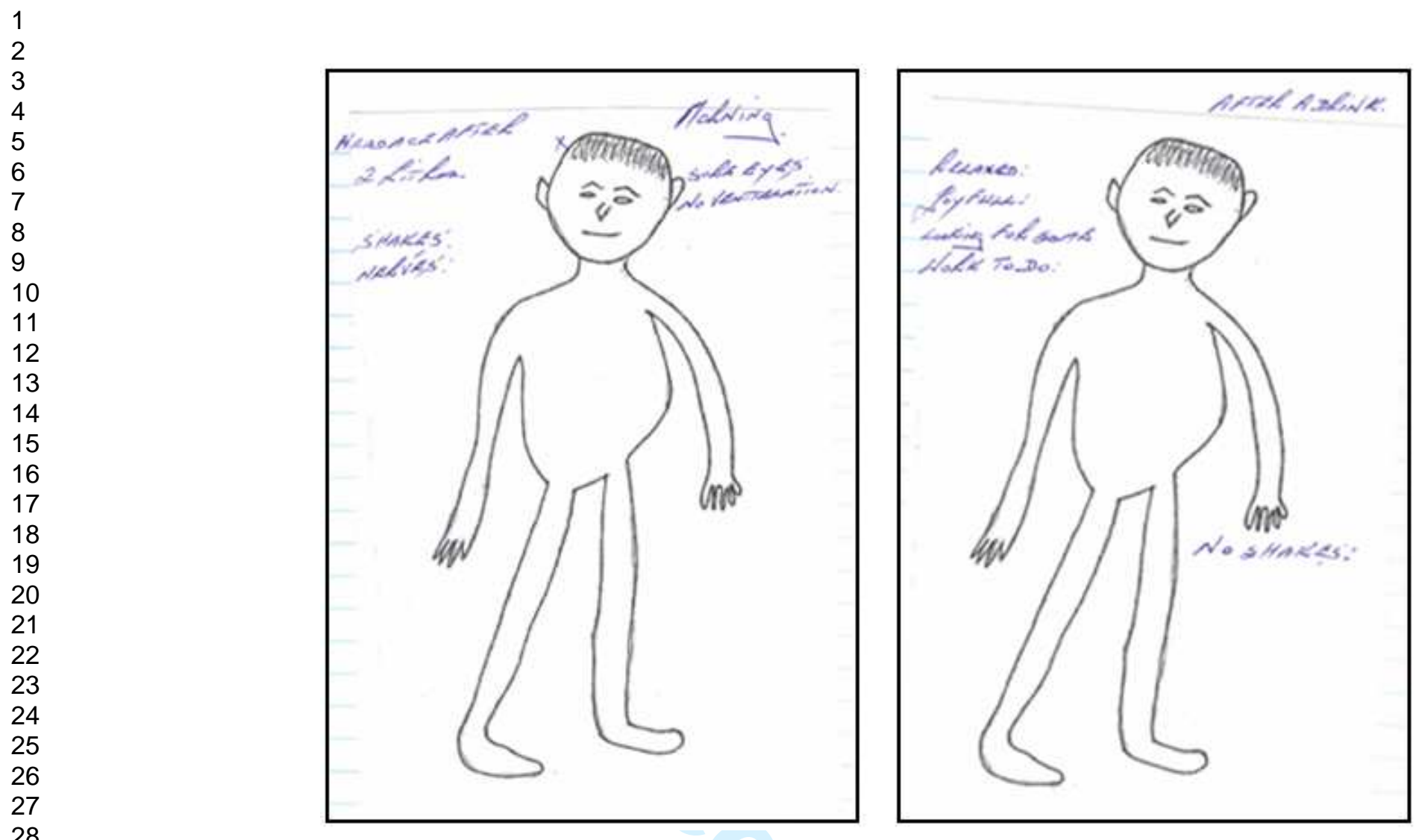

29

Figure 1: Example from BMW's body book

http://mc.manuscriptcentral.com/culturalgeog 


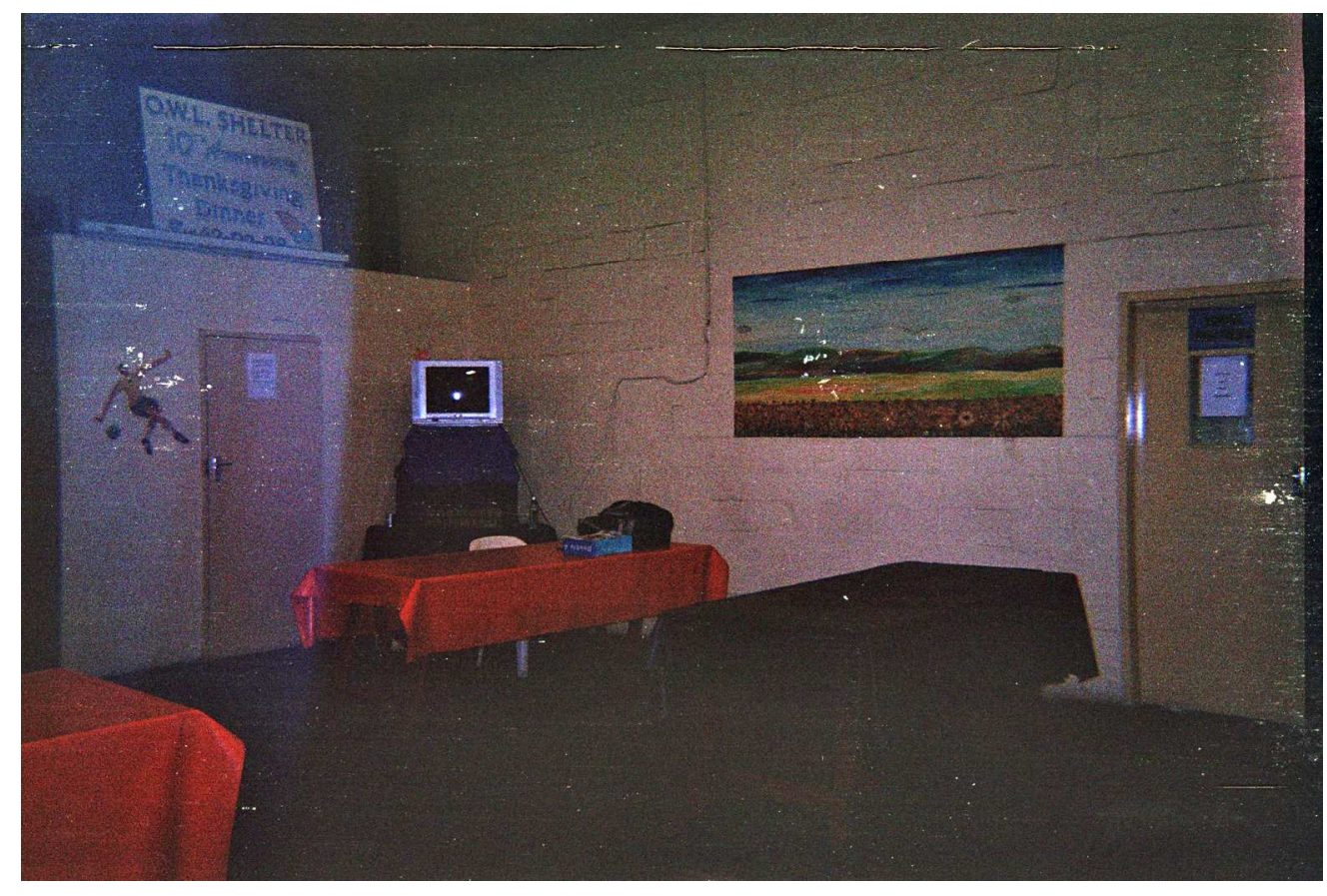

Communal shelter space $694 \times 462 \mathrm{~mm}(72 \times 72$ DPI $)$ 


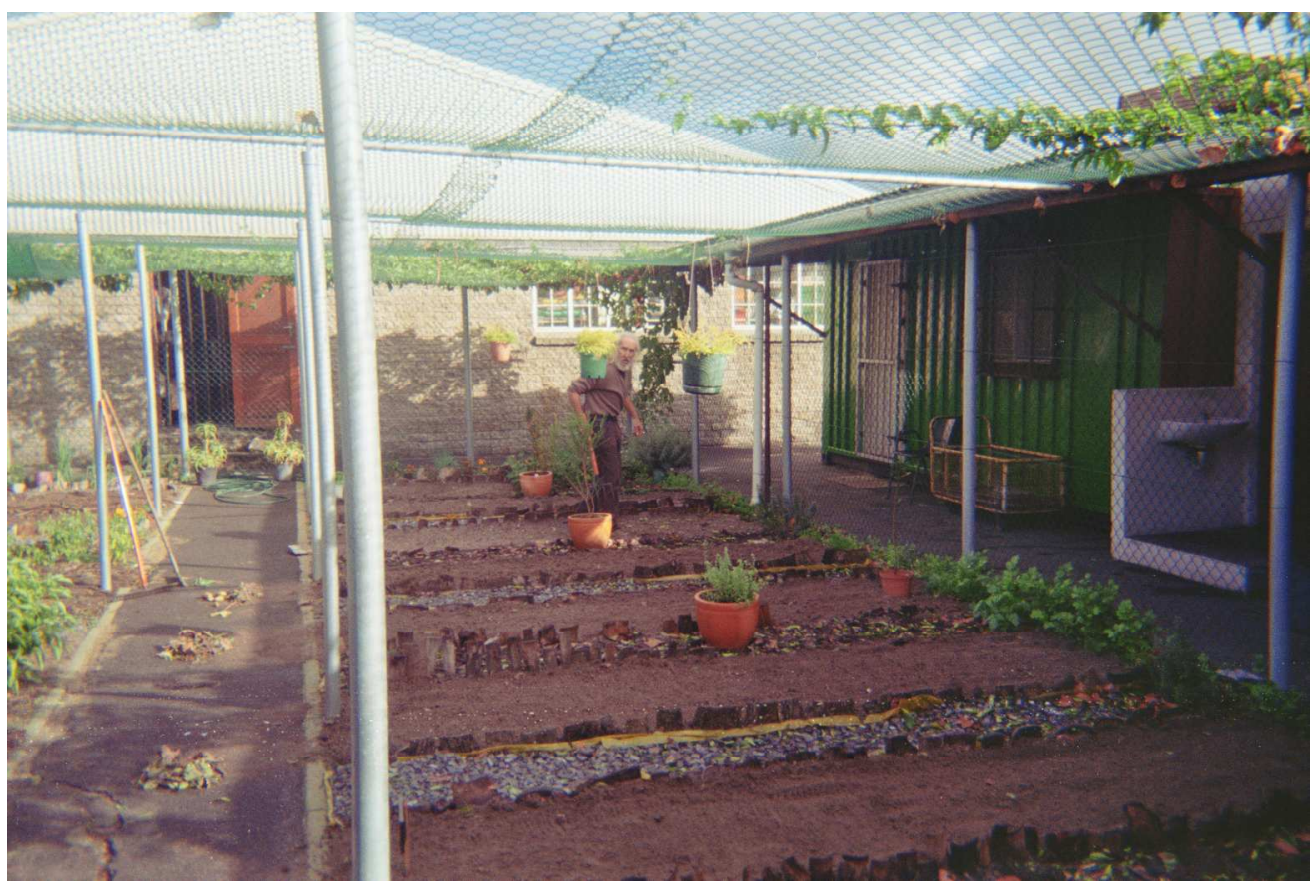

Vegetable garden $1388 \times 925 \mathrm{~mm}(72 \times 72 \mathrm{DPI})$ 


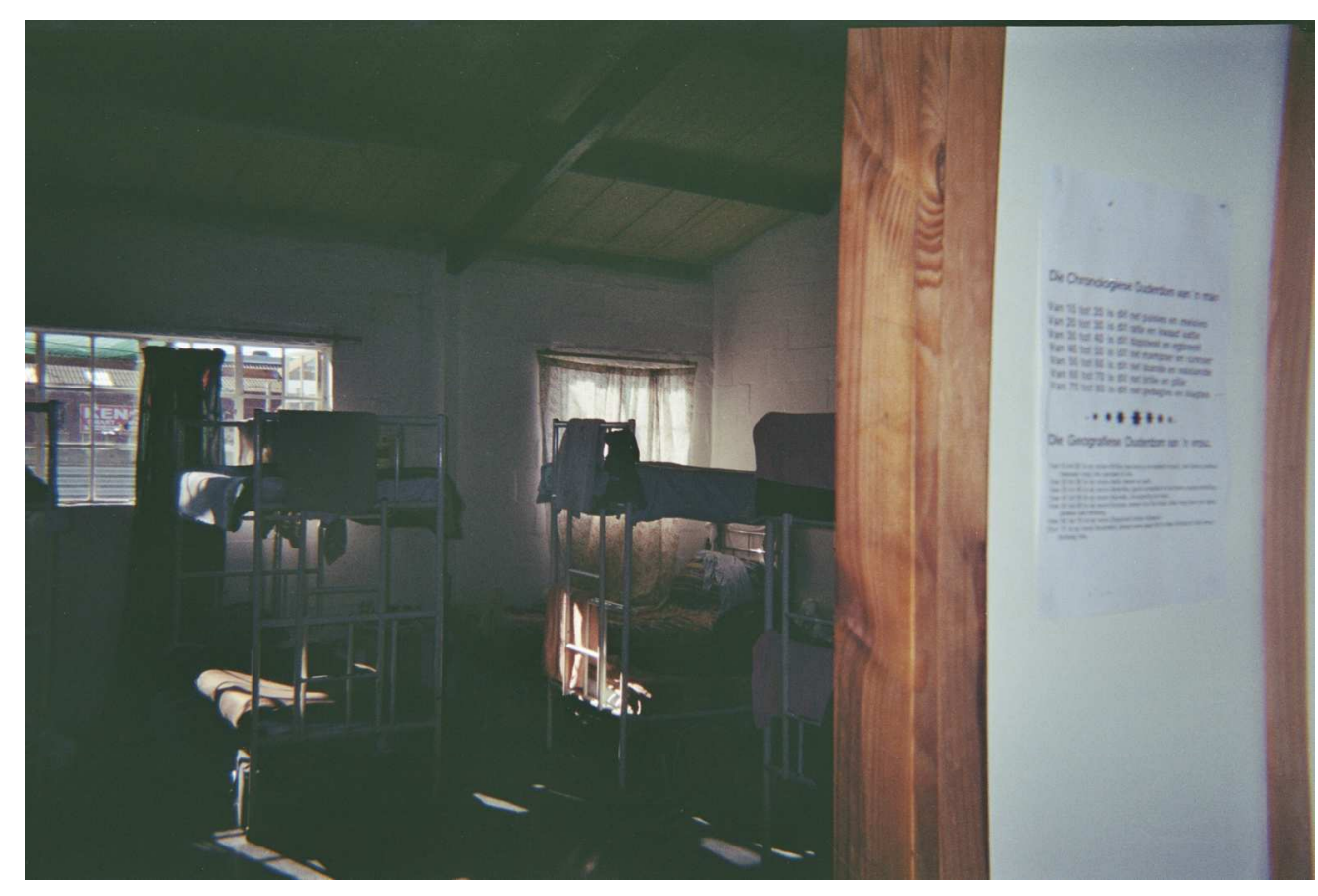

Men's dormitory $520 \times 347 \mathrm{~mm}(96 \times 96$ DPI $)$ 


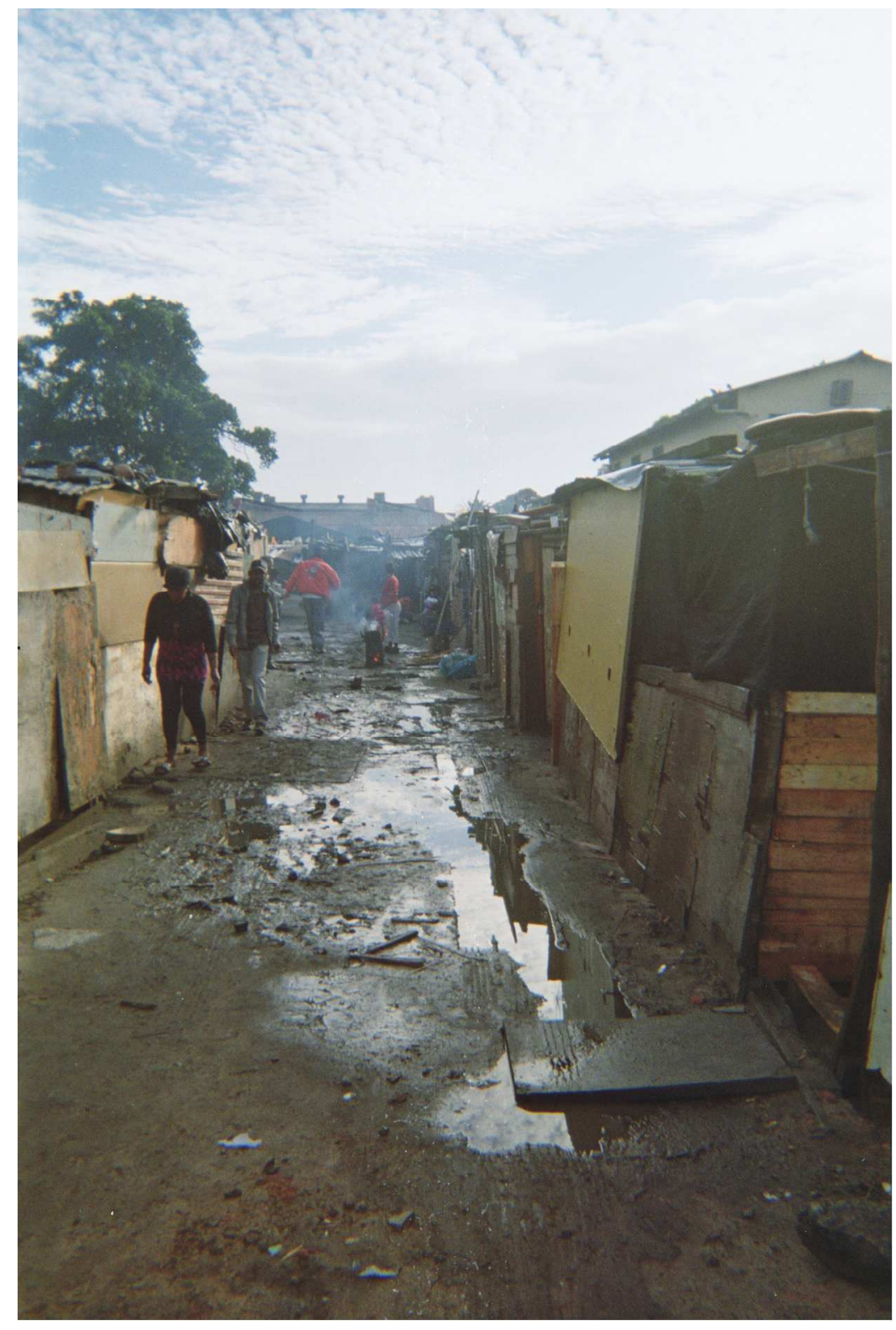

Path through informal settlement $925 \times 1388 \mathrm{~mm}(72 \times 72$ DPI $)$ 


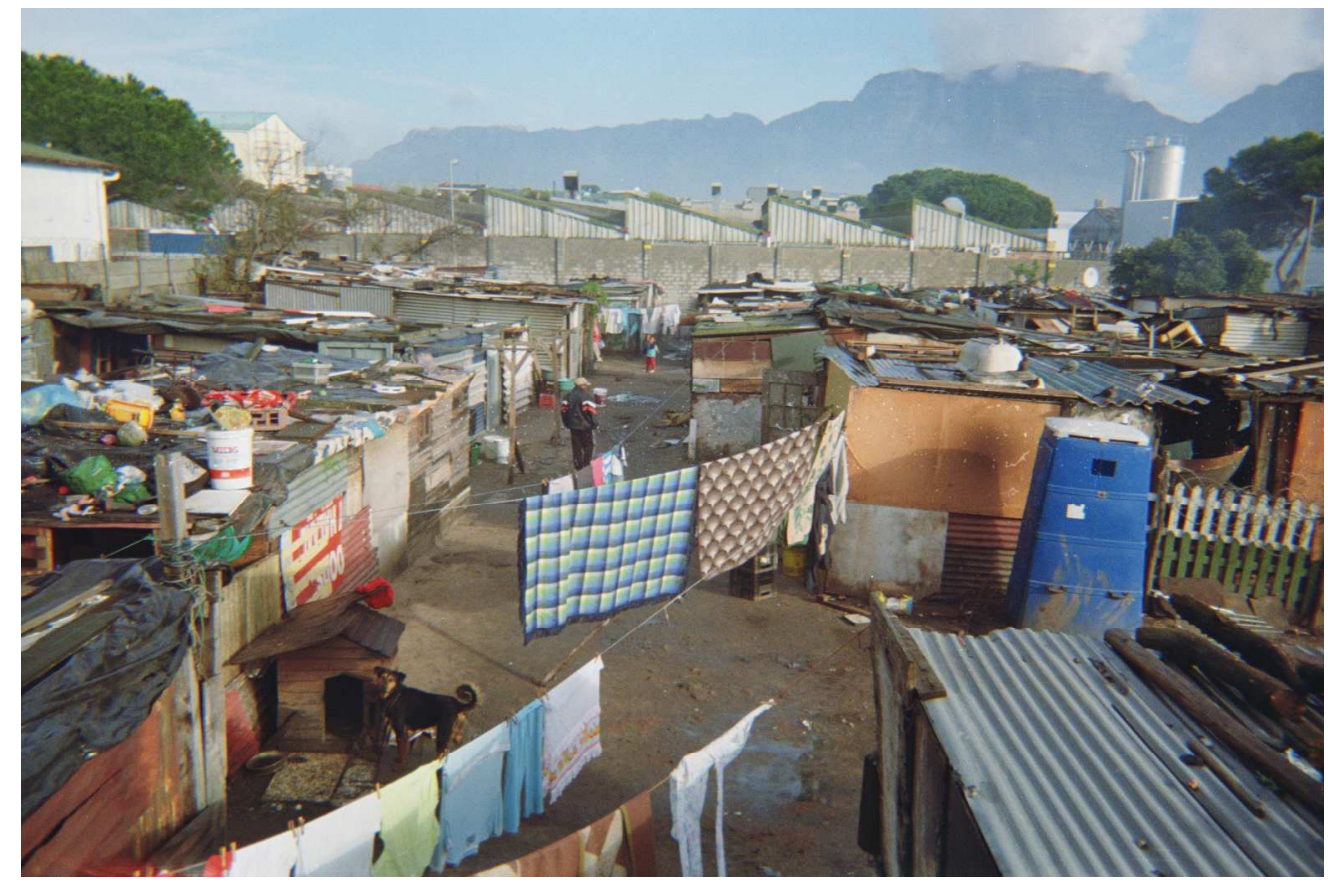

Shacks

$1388 \times 925 \mathrm{~mm}(72 \times 72$ DPI $)$ 


\section{Page 35 of 36} cultural geographies

1

2

3

4

5

6
7

8

9

10

11

12

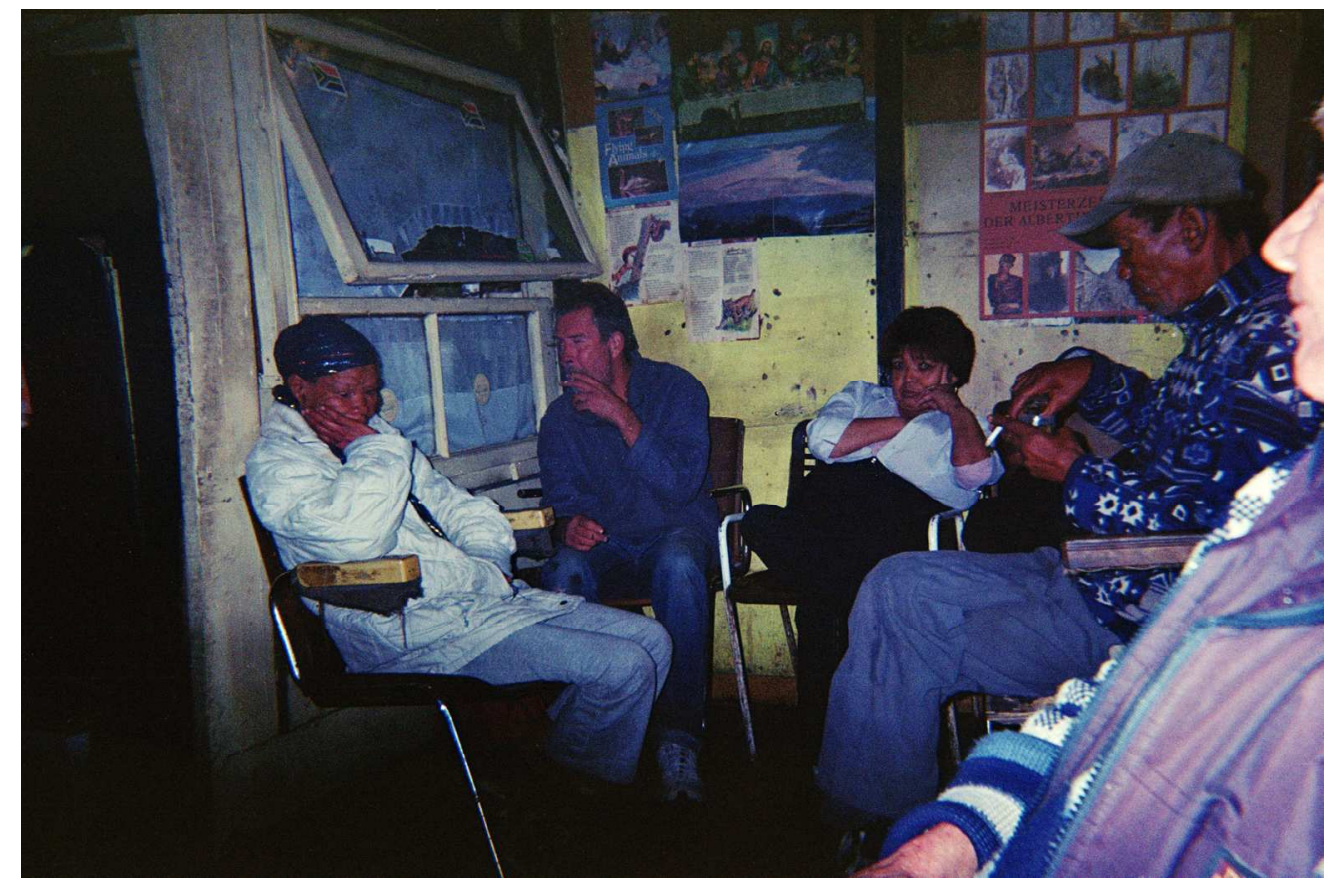

Shebeen $694 \times 462 \mathrm{~mm}(72 \times 72 \mathrm{DPI})$ 


\section{List of figures}

1. Figure 1: BMW's body book

2. Communal shelter space (Photo: Wilkins)

3. Vegetable garden (Photo: Research participant)

4. Men's dormitory (Photo: Research participant)

5. Path through informal settlement (Photo: Research participant)

6. Shacks in informal settlement (Photo: Research participant)

7. Shebeen (Photo: Research participant) 